\title{
Prognostic Factors and Survival Rate of Childhood Acute Lymphoblastic Leukemia in Eastern Indonesia: Kaplan-Meier and Cox Regression Approach
}

\author{
A. A. Arsunan ${ }^{1 *}$, Rezki Elisafitri ${ }^{1}$, Atjo Wahyu $^{2}$, Aisyah Aisyah $^{3}$ \\ ${ }^{1}$ Department of Epidemiology, Faculty of Public Health, Hasanuddin University, Makassar, Indonesia; ${ }^{2}$ Department of \\ Occupational Health and Safety, Faculty of Public Health, Hasanuddin University, Makassar, Indonesia; ${ }^{3}$ Department of \\ Agribusiness, Pangkajene Kepulauan Polytechnic Agricultural, Pangkajene, Indonesia
}

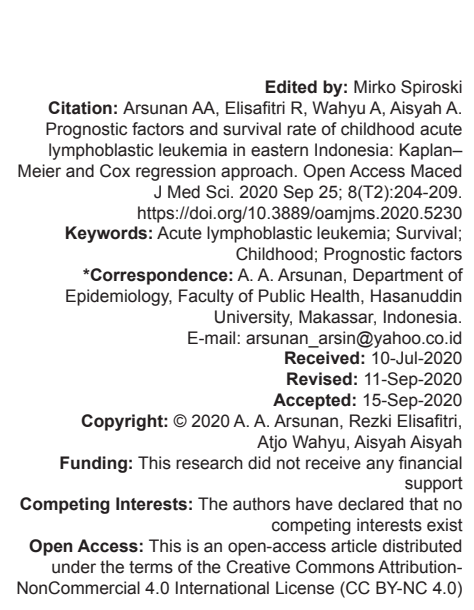

\begin{abstract}
BACKGROUND: Acute lymphoblastic leukemia (ALL) is one of the most common childhood hematological malignancies with an incident each year that tends to increase.

AIM: This study aims to determine the survival rate of childhood ALL in Dr. Wahidin Sudirohusodo General Hospita and the prognostic factors that influence it.

METHODS: A retrospective cohort design was conducted among childhood ALL. The samples were patients ALL diagnosed since January 1, 2014, until 31, 2017, in Dr. Wahidin Sudirohusodo General Hospital. A total of 109 patients were selected by simple random sampling. Data collected through medical records observations. Data were analyzed using Kaplan-Meier and Cox regression analysis.

RESULTS: The cumulative survival rate of childhood ALL was $26 \%$. The prognostic factors associated with survival of childhood ALL were nutritional status $(p=0.028)$, leukocyte counts $(p=0.000)$, platelet counts $(p=0.000)$, and comorbidity $(p=0.000)$. Based on multivariate analysis with Cox regression, the most influencing prognostic factor on survival of ALL patients was comorbidity ( $p=0.000$, hazard ratio $=3.699$ confidence interval 95\% 1.945-7.033). Childhood ALL with comorbidities had a risk of death 3699 times higher than childhood ALL without comorbidities.

CONCLUSION: Nutritional status, leukocyte counts, platelet counts, and comorbidity were prognostic factors that influence survival of childhood ALL. Comorbidity was the most influencing prognostic factor on survival of childhood ALL.
\end{abstract}

\section{Introduction}

Cancer is one of the leading causes of death worldwide, including blood cancer or often called leukemia. Acute leukemia is the most common type of cancer among childhood, accounting for $97 \%$ of all leukemia types [1]. Acute lymphoblastic leukemia (ALL) is one of the most common childhood malignancies with an increasing incidence every year. Based on facts 2016-2017 data by leukemia and lymphoma society (LLS), in 2009-2013, ALL accounted for $74.5 \%$ of new leukemia cases in childhood younger than 20 years [2].

The most common type of cancer suffered by childhood in Indonesia is leukemia [3]. The prevalence of ALL in South Sulawesi Province based on medical record data of Dr. Wahidin Sudirohusodo General Hospital in Makassar for the last 3 years tends to increase and is a disease with the highest number of cases in child care. In 2015, there are 60 cases, increasing by 2016 to 63 cases, and by 2017, there are 67 cases [4].
The survival rate is a measure of the success of disease treatment. Leukemia prognostic factor becomes the doctor's benchmark in determining the treatment to be given to the patient. A poor prognostic affects the body's resistance to illness. ALL prognostic factors include nutritional status, leukocyte counts, platelet counts, and comorbidity [1], [5].

Nutritional status of patients with ALL at the time of diagnosis has an effect on the outcome of leukemia treatment. Obesity affects childhood, who suffers from ALL. Obese patients with ALL had a significantly worse survival than non-obese patients [6]. In addition, the study in Belanda found that underweight at the time of ALL diagnosis was a risk factor for relapse and decreased body mass index during treatment was associated with reduced survival [7]. The number of leukocytes is a factor frequently identified in ALL patients. Patients with leukocyte count $>50,000 \mu \mathrm{l}$ were associated with a low survival rate [8]. A study in Brazil found that the leukocyte counts of ALL patients had a significant effect on survival rate [9]. Leukemia can decrease platelet production if cancer cells spread 
to the bone marrow. Patients with leukemia who have platelets $<30,000 \mu \mathrm{l}$ have a poor prognostic. Platelet counts were a prognostic factor that influenced the survival of childhood with ALL [10]. Leukemia is a disease of abnormal white blood cells that are immune cells of the human body. Disruption white blood cells make the body easy to get the disease, especially infectious diseases. Comorbidity is a poor prognostic factor for leukemia patients [11].

Several studies related to survival and ALL prognostic factors performed in some countries, especially in developed countries, have proved that prognostic factors such as nutritional status, leukocyte counts, platelet counts, and comorbidity are significantly associated with ALL survival in childhood. By examining the survival rate of leukemia patients, it can assist in the development of leukemia information and its prevention in the future. This study aims to determine the survival rates of patients with ALL in childhood in Dr. Wahidin Sudirohusodo General Hospital and the prognostic factors that influence it.

\section{Materials and Methods}

This study was conducted at Dr. Wahidin Sudirohusodo General Hospital, Makassar, South Sulawesi, Eastern Indonesia. The type of research used was observational analytic with retrospective cohort design. The population in this study was ALL patients diagnosed since January 1, 2014, until 31, 2017. A total of 109 patients were selected by simple random sampling. Sample criteria in this study were childhood aged $0-18$ years when first diagnosed ALL and have a complete medical record and meet the criteria of variables studied.

Data were conducted through ALL patients medical record observations. The instrument used is the observation sheet. From the patient's medical record, data were collected according to the research needs such as gender, address, telephone number, type of financing, date of first visit and date of exit or date of last visit, date of birth, diagnosis age, nutritional status, ALL characteristics, number of leukocytes, platelet counts, comorbidity, and patient status (life or death). In addition to data collection through medical record search, researchers also conducted a search through the telephone communication media to ask the patient's status to the parents or family of patients. If the phone number of the parents or family of the patient cannot be contacted, then the determination of the patient's status is based on the patient's last condition at the last hospital control, as recorded in the patient's medical record. When the patient comes out in good condition, then the patient is categorized as a sensor (survive), whereas if the patient goes out in bad condition, then the patient is categorized as the event (death).

Univariate analysis aims to describe the distribution of patient characteristics and research variables. Bivariate analysis was performed to determine the probability difference of survival of ALL patients based on the prognosis factor using Kaplan-Meier method with the log-rank test. Multivariate analysis was performed to determine the most influencing variable on survival of ALL patients using Cox regression (proportional hazard $[\mathrm{PH}]$ model), test performed simultaneously for variables that meet assumptions of proportional hazard.

\section{Results}

Table 1 shows the characteristics of the sample in this study. Of 109 LLA patients, most patients died $(63.3 \%)$ compared to patients who survived. The majority of ALL patients were in the 1-10 year age group (76.1\%). Most ALL patients were men (60.6\%). Based

Table 1: Distribution of patient characteristics

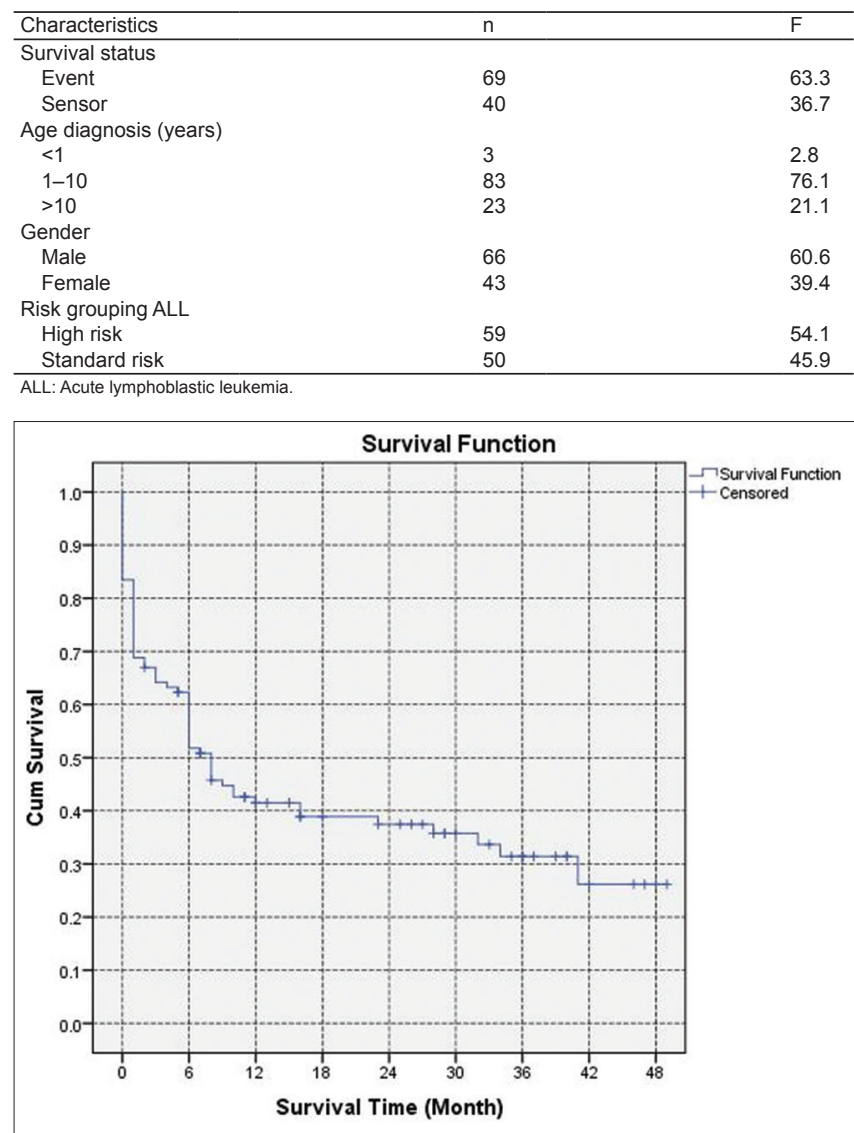

Figure 1: Survival rate childhood acute lymphoblastic leukemia

on ALL risk grouping, according to the National Cancer Institute, more than half of ALL patients (54.1\%) are categories high risk. The cumulative proportion of ALL survival in childhood who reached 4 years (48 months) was $26 \%$ (Figure 1). 
Most of the ALL patients who died were patients with abnormal nutritional status (71.4\%). Based on leukocyte counts and platelet counts, most of the ALL patients who died were patients with leukocyte counts $>50,000 \mu \mathrm{l}(82.9 \%)$ and platelet counts <30,000 $\mu \mathrm{l}$ $(82.1 \%)$. Based on comorbidity, the most died patients in patients with comorbidity (85.1\%) (Table 2). Differences in the survival of patients with ALL in childhood based on prognostic factors are presented in Figure 2. The survival curve of ALL patients based on nutritional status, leukocyte counts, platelet counts, and comorbidity do not intersect. This shows the assumption $\mathrm{PH}$ fulfilled, with p-value (log rank) $<0.05$. That is, there is a significant relationship between nutritional status, leukocyte counts, platelet counts, and comorbidity with the survival of ALL patients.

Table 2: Distribution of LLA patients based on research variables and survival status

\begin{tabular}{|c|c|c|c|c|c|c|c|}
\hline \multirow[t]{3}{*}{ Research variable } & \multicolumn{4}{|c|}{ Survival status } & \multirow{2}{*}{\multicolumn{2}{|c|}{ Total }} & \multirow[t]{3}{*}{$p$ (log rank) } \\
\hline & \multicolumn{2}{|c|}{ Died } & \multicolumn{2}{|c|}{ Survive } & & & \\
\hline & $\mathrm{n}$ & $\mathrm{F}$ & $n$ & $\mathrm{~F}$ & $n$ & $\mathrm{~F}$ & \\
\hline Nutritional status & & & & & & & $0.028^{*}$ \\
\hline Abnormal & 50 & 71.4 & 20 & 28.6 & 70 & 100 & \\
\hline Normal & 19 & 48.7 & 20 & 51.3 & 39 & 100 & \\
\hline Leukocyte counts $(\mu \mathrm{l})$ & & & & & & & $0.000^{*}$ \\
\hline$>50,000$ & 29 & 82.9 & 6 & 17.1 & 35 & 100 & \\
\hline$<50,000$ & 40 & 54.1 & 34 & 45.9 & 74 & 100 & \\
\hline Platelet counts $(\mu \mathrm{l})$ & & & & & & & $0.000^{*}$ \\
\hline$<30,000$ & 46 & 82.1 & 10 & 17.9 & 56 & 100 & \\
\hline$>30,000$ & 23 & 43.3 & 30 & 56.6 & 53 & 100 & \\
\hline Comorbidity & & & & & & & $0.000^{*}$ \\
\hline Yes & 57 & 85.1 & 10 & 14.9 & 67 & 100 & \\
\hline No & 12 & 28.6 & 30 & 71.4 & 42 & 100 & \\
\hline
\end{tabular}

ALL patients survival rate based on nutritional status that is abnormal nutrition was $16 \%$, whereas normal nutrition was $46 \%$. The survival rate based on the leukocyte counts is the leukocyte counts $>50,000$ $\mu \mathrm{l}$ was $8 \%$, while the leukocyte counts $<50,000 \mu$ l was $34 \%$. The survival rate based on the platelet counts is the platelet counts $<30,000 \mu \mathrm{l}$ was $13 \%$, whereas the platelet counts $>30,000 \mu \mathrm{l}$ was $41 \%$. The survival rate of ALL patients is based on comorbidity which was $8 \%$ and without comorbidity was $70 \%$ (Figure 2).

Table 3 shows that variables having $p<0.05$ were platelet counts and comorbidity. Among the two variables, the comorbidity variable has the highest hazard ratio value of 3.699 confidence interval 95\% 1.945-7.033. Thus, comorbidity is the variable that has the most dominant influence on survival of ALL patients. Childhood ALL with comorbidities had a risk of death 3699 times higher than childhood ALL without comorbidities.

Table 3: Results Cox regression analysis multivariate

\begin{tabular}{llllllll}
\hline Variable & B & SE & Wald & Sig. & HR & \multicolumn{2}{c}{$95 \%$ Cl for HR } \\
\cline { 6 - 8 } & & & & & & Lower & Upper \\
\hline Nutritional status & -0.96 & 0.303 & 0.101 & 0.750 & 0.908 & 0.501 & 1.645 \\
Leukocyte counts & 0.357 & 0.259 & 1.907 & 0.167 & 1.430 & 0.861 & 2.375 \\
Platelet counts & 1.107 & 0.300 & 13.637 & 0.000 & 3.027 & 3.027 & 5.448 \\
Comorbidity & 1.308 & 0.328 & 15.913 & 0.000 & 3.699 & 1.945 & 7.033 \\
\hline Cl: Confidence interval, HR: Hazard ratio, SE: Standard error. & & & &
\end{tabular}

\section{Discussion}

This study shows that the 4-year survival rate of childhood ALL in Dr. Wahidin Sudirohusodo General
Hospital was $26 \%$. Prognosis factors associated with the survival rate of childhood ALL were nutritional status, leukocyte counts, platelet counts, and comorbidity.

Survival rate in this study was lower than a study in Yogyakarta, where the survival rate of childhood with ALL was $56.1 \%$ [12]. In addition, there was a significant difference between ALL survival rates in this study and two studies conducted in Brazil and Germany [13], [14]. Survival rates of both studies are over $75 \%$. This shows the survival rate of ALL patients in developing countries is still very low when compared with developed countries as Brazil and Germany. The difference in survival rates for patients with ALL is likely due to differences in patient conditions such as individual factors, cancer factors, and leukemia management factors in each study site. In addition, follow-up different lengths of also caused a difference in survival rate.

The low proportion of survival of ALL patients in childhood diagnosed in Dr. Wahidin Sudirohusodo Makassar is caused by several factors, as there are many patients who refuse chemotherapy and do not continue treatment because of side effects caused by a combination of cytostatic drugs on chemotherapy treatment. In addition, many patients are returning at their own request under adverse conditions so that many ALL patients die of not continuing treatment.

One of the prognostic factors associated with survival of patients with ALL in childhood in Dr. Wahidin Sudirohusodo General Hospital is nutritional status. Most ALL patients with abnormal nutritional status $(71.4 \%)$ were died. The proportion of survival of patients with abnormal nutrition is lower than that of $A L L$ patients with normal nutrition. The results of this study are in line with research Eissa, Galilee, and Orgel, who concluded that obesity affects the prognosis of ALL patients in childhood [6], [15], [16]. Obese patients with ALL had a significantly worse survival than non-obese patients. One of the risk factors for leukemia is due to gene mutation. Obesity may speed up the rate of cell mutation or disrupt the cellular mechanism of DNA repair that results in mutation events [17]. Therefore, ALL patients with abnormal nutrition tend to have a poor prognosis. It is important to develop interventions to reduce obesity prevalence by a focus on behavioral therapy [18].

The study also showed a correlation between leukocyte counts and survival of ALL patients in childhood. The most deaths were in patients with leukocyte counts $>50,000 \mu \mathrm{l}(82.9 \%)$. The proportion of survival of patients with leukocyte counts $>50,000$ $\mu$ l was lower than that in ALL patients with leukocyte counts $<50,000 \mu \mathrm{l}$. The results of this study are in line with research Sousa, Rujkijyanont, Gupta, and Parvareh who found that the number of leukocytes at the time of diagnosis was related to the probability of survival of childhood with ALL [9], [19], [20], [21]. The leukocyte 

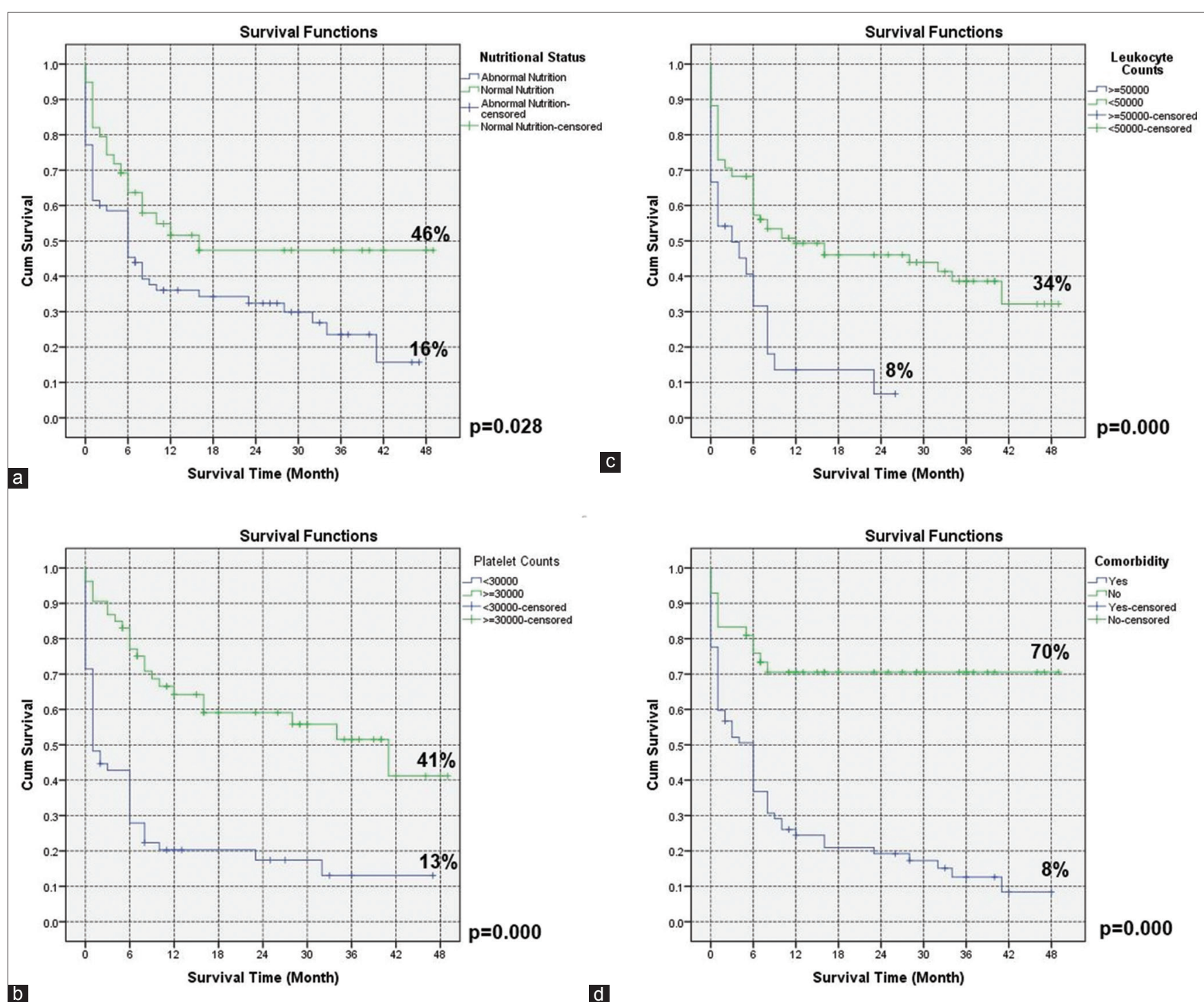

Figure 2: (a-d) Survival rate childhood acute lymphoblastic leukemia according to nutritional status, leukocyte count, platelet count, and comorbidity with Kaplan-Meier method

counts above $100 \times 109 / \mathrm{L}$ is a prognostic factor of induction phase failure in chemotherapy treatment [22].

Leukemia can decrease platelet production if cancer cells spread to the bone marrow. This study found an association between platelet counts and survival of ALL patients in childhood. Most patients with platelet counts $<30,000 \mu \mathrm{l}(82.1 \%)$ were died. The proportion of survival in patients with platelet counts $<30,000 \mu$ l lower than the ALL patients with platelet counts $>30,000 \mu \mathrm{l}$. Patients with platelet counts $<30,000 \mu$ may experience bleeding even if under no activity conditions. This may worsen the condition of the ALL patient. The results of this study were not different from those of AlmasiHashiani in Iran and Kulkarni in India, which found that platelet counts were a prognostic factor that influenced the survival of childhood with ALL [10], [23]. The results of this study are also in line with the theory that patients with ALL who have platelet counts $<30,000 / \mathrm{mm}^{3}$ have a poor prognosis [5].

The comorbidities in this study were comorbidities other than ALL diagnoses that occurred when patients underwent treatment that could affect the patient's condition. The results of this study indicate an association between comorbidity and survival of ALL patients. The most deaths were in patients with comorbidity $(85.1 \%)$. The presence of comorbidity is a poor prognostic factor for leukemia patients. The most common comorbidities in this study were thrombocytopenia $(48.6 \%)$, then anemia $(47.7 \%)$, neutropenia $(31.2 \%)$, hyperleukocytosis (21.1\%), underweight (20.2\%), sepsis $(17.4 \%)$, and caries dentist (13.8\%). Most ALL patients have comorbidities of more than one disease. The results of this study are in line with Simanjorang's research, which concluded that patients with comorbidity had $5 \%$ survival probability of $0 \%$ [11]. That is, patients who have comorbidities have died before 5 years. Disruption of white blood cells causes the body easy to get the disease. In addition, leukemia patients become susceptible to other diseases due to interventions such as chemotherapy, stem cell transplantation, and radiation that can cause deficiency of the body. The therapy also results in skin and mucosal growth 
disorders in the digestive tract making it susceptible to bacterial infections [24].

\section{Conclusion}

Survival rate of childhood ALL in Dr. Wahidin Sudirohusodo General Hospital Makassar was 26\%. The prognostic factors significantly associated with ALL survival were nutritional status, leukocyte counts, platelet counts, and comorbidity. The most influential prognostic factor for ALL survival is comorbidity. Stratification of leukemia treatment based on prognostic factors associated with ALL patient survival needs to be done to improve treatment success.

\section{Recommendation}

Research needs to be done on the evaluation of cytostatic side effects on the treatment of leukemia (chemotherapy) to prevent the occurrence of comorbidities in ALL patients that may affect the outcome of patient treatment.

\section{References}

1. Permono B, Ugrasena I. Buku Ajar Hematologi-Onkologi Anak. Jakarta: Ikatan Dokter Anak Indonesia; 2012.

2. LLS. Fact 2016-2017. New York: Leukemia \& Lymphoma Society; 2018.

3. Kemenkes RI. Control Cancer in Children. Jakarta: Republic of Indonesia's Ministry of Health; 2016.

4. Medical Record of Dr. Wahidin Sudirohusodo General Hospital Makassar. Data on Acute Leukemia Inpatient Patients 20122017. Makassar: Dr. Wahidin Sudirohusodo General Hospital Makassar; 2018. https://doi.org/10.15562/jdmfs.v13i3.413

5. Wirawan. Diagnostic acute lymphocytic leukemia: Morphology, immunophenotype, cytogenetic, and molecular. Majalah Kedok Indones. 2003;53(1).

6. Eissa H, Zhou Y, Panetta J, Browne E, Jeha S, Cheng C, et al. The effect of body mass index at diagnosis on clinical outcome in children with newly diagnosed acute lymphoblastic leukemia. Blood Cancer J. 2017;7(2):e531. https://doi.org/10.1038/ bcj.2017.11

PMid:28212374

7. Hoed M, Pluijm SM, de Groot-Kruseman HA, Te Winkel ML, van den Akker EL, Hoogerbrugge $\mathrm{P}$, et al. The negative impact of being underweight and weight loss on survival of children with acute lymphoblastic leukemia. Haematologica. 2015;100(1):629. https://doi.org/10.3324/haematol.2014.110668 PMid:25304613

8. Robison LL. Late effects of acute lymphoblastic leukemia therapy in patients diagnosed at 0-20 years of age. Hematology Am Soc Hematol Educ Program. 2011;2011(1):238-42. https:// doi.org/10.1182/asheducation-2011.1.238

PMid:22160040
9. Sousa DW, Ferreira FV, Félix FH, Lopes MV. Acute lymphoblastic leukemia in children and adolescents: Prognostic factors and analysis of survival. Rev Bras Hematol Hemoter. 2015;37(4):223-9.

10. Almasi-Hashiani A, Zareifar S, Karimi M, Khedmati E, Mohammadbeigi A. Survival rate of childhood leukemia in Shiraz, Southern Iran. Iran J Pediatr. 2013;23(1):53-8. PMid:23550191

11. Simanjorang C, Kodim N, Tehuteru E. 5-year survival difference acute lymphoblastic leukemia patients and acute mieloblastic leukemia in children at "Dharmais" cancer hospital, Jakarta, 1997-2008. Indones J Cancer. 2013;7(1):15-21.

12. Wijayanti LP, Supriyadi E. Faktor prognostics and survival of children acute lymphoblastic leukemia patients in $\mathrm{Dr}$ Sardjito Hospital, Yogyakarta, 2010-2015. Indones J Cancer. 2017;11(4):145-50.

13. Lins MM, Santos MO, Albuquerque MF, Castro CC, Mello MJ, Camargo B. Incidence and survival of childhood leukemia in Recife, Brazil: A population-based analysis. Pediatr Blood Cancer. 2017;64(8):1-6. https://doi.org/10.1002/pbc.26391 PMid:28000427

14. Erdmann F, Kaatsch P, Zeeb H, Roman E, Lightfoot T, Schüz J. Survival from childhood acute lymphoblastic leukaemia in West Germany: Does socio-demographic background matter? Eur J Cancer. 2014;50(7):1345-53. https://doi.org/10.1016/j. ejca.2014.01.028

15. Gelelete CB, Pereira SH, Azevedo AM, Thiago LS, Mundim M, Land MG, et al. Overweight as a prognostic factor in children with acute lymphoblastic leukemia. Obesity (Silver Spring). 2011;19(9):1908-11. https://doi.org/10.1038/oby.2011.195 PMid:21720424

16. Orgel E, Tucci J, Alhushki W, Malvar J, Sposto R, Fu CH, et al. Obesity is associated with residual leukemia following induction therapy for childhood B-precursor acute lymphoblastic leukemia. Blood. 2014;124(26):3932-8. https://doi.org/10.1182/ blood-2014-08-595389

PMid:25349177

17. Lichtman MA. Obesity and the risk for a hematological malignancy: Leukemia, lymphoma, or myeloma. Oncologist. 2010;15(10):1083-101. https://doi.org/10.1634/ theoncologist.2010-0206 PMid:20930095

18. Asnidar A, Arsunan AA, Ayu EK, Suriah, Muriyati. Knowledge, food intake pattern, and body mass index of overweight and obese adolescent before and after giving social media health education in Bulukumba regency. Indian J Public Health Res Dev. 2018;9(9):160-5. https://doi. org/10.5958/0976-5506.2018.00987.7

19. Rujkijyanont $P$, Kaewinsang $S$, Monsereenusorn $C$, Traivaree $C$. Pediatric acute leukemia: The effect of prognostic factors on clinical outcomes at phramongkutklao hospital, Bangkok, Thailand. J Med Assoc Thai. 2014;97(2):S188-95. PMid:25518193

20. Gupta S, Sutradhar R, Guttmann A, Sung L, Pole JD. Socioeconomic status and event free survival in pediatric acute lymphoblastic leukemia: A population-based cohort study. Leuk Res. 2014;38(12):1407-12. https://doi.org/10.1016/j. leukres.2014.08.017 PMid:25224660

21. Parvareh $\mathrm{M}$, Khanjani $\mathrm{N}$. The survival of childhood leukemia and its related factors in Kerman, Iran. Iran J Health Sci. 2015;3(4):24-32.

22. Oudot C, Auclerc MF, Levy V, Porcher R, Piguet C, Pere $\mathrm{Y}$, et al. Prognostic factors for leukemic induction failure in children with acute lymphoblastic leukemia and outcome after salvage therapy: The FRALLE 93 study. J Clin Oncol. 
2008;26(9):1496-503. https://doi.org/10.1200/jco.2007.12.2820 PMid:18349402

23. Kulkarni KP, Marwaha RK, Trehan A, Bansal D. Survival outcome in childhood ALL: Experience from a tertiary care Centre in North India. Pediatr Blood Cancer. 2009;53(2):168-73. https://doi.org/10.1002/pbc.21897

24. Hadianto MT. Differences in Interleukin-8 Levels in Bacterial Infection and Non-Infection in Leukemia Children with Neutropenia Fever, Thesis. Indonesia: Diponegoro University; 2011. 